\title{
Prognostic relevance of melanoma antigen D1 expression in colorectal carcinoma
}

\author{
Zhao-lei Zeng ${ }^{1,2+}$, Wen-jing Wu $\mathbf{u}^{1,3}$, Jing Yang ${ }^{1,2}$, Zhen-jie Tang ${ }^{1,2}$, Dong-liang Chen ${ }^{1,3}$, Miao-zhen Qiu ${ }^{1,3}$, \\ Hui-yan Luo ${ }^{1,3}$, Zhi-qiang Wang ${ }^{1,3}$, Ying Jin ${ }^{1,3}$, De-shen Wang ${ }^{1,3}$ and Rui-hua Xu $\mathbf{u}^{1,3^{*}}$
}

\begin{abstract}
Background: Melanoma antigen D1 (MAGED1) is a member of the type II melanoma antigen (MAGE) family. The down-regulation of MAGED1 expression has been shown in breast carcinoma cell lines and in glioma stem cells and may play an important role in apoptosis and anti-tumorigenesis. However, there is no report on its clinical role in colorectal cancer (CRC).

Methods: We examined the expression of MAGED1 by qPCR in colorectal cancer tissues and their adjacent nontumorous tissues taken from 6 cases and performed Western blotting and IHC analyses. In addition, we analyzed MAGED1 expression in 285 clinicopathologically characterized colorectal cancer patients.

Results: MAGED1 expression was significantly down-regulated in colorectal cancer tissues compared with adjacent non-tumorous tissues and was associated with clinical stage $(p<0.001)$, T classification $(p=0.001)$, N classification $(p<0.001)$, M classification $(p<0.001)$ and pathologic differentiation $(p=0.002)$. Patients with lower MAGED1 expression had a shorter survival time than those with higher MAGED1 expression. Univariate and multivariate analyses indicated that MAGED1 expression was an independent prognostic factors $(p<0.001)$.
\end{abstract}

Conclusions: MAGED1 may serve as a novel prognostic biomarker of human colorectal cancer.

Keywords: MAGED1, Colorectal cancer, Melanoma antigen and prognosis

\section{Background}

The melanoma antigen (MAGE) family, which includes more than 25 members, is classified into two subfamilies based on the structural differences of the genes and tissuespecific gene expressions. Type I MAGE genes are classically subdivided into three clusters (MAGE-A, B, and $C$ ), which are expressed in a variety of cancer cells, but are seldom expressed in normal cells [1-4]. Type II MAGE genes include MAGE-D (MAGED1 to MAGED14), MAGEE1 to H1, MAGEL2 and NECDIN [5]. In contrast to type I $M A G E$ genes, type II MAGE genes are expressed in a variety of normal tissues and cell lines [6,7].

Melanoma antigen D1 (MAGED1), also known as Dlxin-1 or NRAGE, is a member of the type II MAGE

\footnotetext{
* Correspondence: xurh@sysucc.org.cn

${ }^{\dagger}$ Equal contributors

'State Key Laboratory of Oncology in Southern China, Guangzhou 510060, China

${ }^{3}$ Department of Medical Oncology, Sun Yat-sen University Cancer Center, Guangzhou 510060, China

Full list of author information is available at the end of the article
}

family. It was reported that MAGED1 modulated the transcriptional activity of DLx5/Msx2, regulating osteoblast differentiation during development [8,9]. Unlike the type I MAGE genes, which encode tumor antigens, $M A G E D 1$ encodes a protein involved in the apoptosis pathway. MAGED1 mediates cellular apoptosis and cell cycle arrest through the c-JNK and p53-dependent pathways [10-12], and is also involved in the BRCA2mediated cell proliferation arrest in a p53-independent manner [13].

In addition to normal tissue expression, type II MAGE genes, including $M A G E D 1$, were also detected in cancer cells. It was reported that the expression of MAGED1 was down-regulated in breast carcinoma cell lines [13] and in glioma stem cells [14]. Chung et al. examined the expression profile of MAGE family genes in Taiwanese patients with colorectal cancer and discovered that the type II $M A G E$ genes MAGED12, MAGEF1, and MAGEH1 are frequently up-regulated in tumors [15].

\section{Biomed Central}

(c) 2012 Zeng et al.; licensee BioMed Central Ltd. This is an Open Access article distributed under the terms of the Creative Commons Attribution License (http://creativecommons.org/licenses/by/2.0), which permits unrestricted use, distribution, and reproduction in any medium, provided the original work is properly cited. 
Although MAGED1 may play an important role in apoptosis and anti-tumorigenesis, there are no reports on its clinical role in colorectal cancer. In this study, we investigated MAGED1 expression and its clinical significance in human colorectal cancer. We found that MAGED1 expression was significantly down-regulated in colorectal cancer tissues compared with their adjacent non-tumorous tissues (ANT) and was associated with the clinical features of colorectal cancer. MAGED1 may serve as a novel prognostic biomarker of human colorectal cancer.

\section{Methods}

\section{Patient information and tissue specimens}

This study was conducted on a total of 285 paraffin-embedded, archived CRC primary samples, which were histopathologically and clinically diagnosed at the Sun Yat-sen University Cancer Center from 1999 to 2007. The clinical and clinicopathological classification and stage were determined according to the American Joint Committee on Cancer (AJCC) TNM staging system. Each lesion was graded histologically according to the WHO classification criteria. Overall survival (OS) was defined as the interval between the date of surgery and date of death or the last known follow up. For the use of these clinical materials for research purposes, prior consent of the patients and approval from the Institutional Research Ethics Committee were obtained. Six pairs of colorectal cancer tissue specimens and corresponding adjacent non-tumorous specimens were obtained from patients with CRC who underwent surgical CRC tissue resection at Sun Yat-sen University Cancer Center. Written informed consent was obtained from each patient before surgery. All excised samples were obtained within $1 \mathrm{~h}$ after the operation from tumor tissues and corresponding adjacent non-tumorous specimens $5-10 \mathrm{~cm}$ from the tumor. For all excised tissues, half of each specimen was placed into liquid nitrogen until further analysis and the remainder was fixed by formalin processed for immunohistochemistry (IHC). The clinical information related to the 285 CRC samples is described in detail in Table 1.

RNA extraction, reverse transcription and real-time PCR

Total RNAs from 6 pairs of tumor tissues and nontumorous tissues was extracted using Trizol reagent (Invitrogen, Carlsbad, California, USA) according to the manufacturer's instructions. First-strand cDNA was synthesized by reverse transcriptase (Invitrogen, Carlsbad, California, USA) using total RNA as a template. Real-time PCR was carried out using an ABI Prism 7500 Sequence Detection System (Applied Biosystems, Foster City, California, USA). The sequences of the primers were as follows: MAGED1: sense primer, 5' GATTCCCTCAGACCTTTGC; anti-sense
Table 1 Clinical data of 285 samples of colorectal cancer

\begin{tabular}{|c|c|}
\hline & Number of cases (\%) \\
\hline \multicolumn{2}{|l|}{ Gender } \\
\hline Male & $183(64.2)$ \\
\hline Female & $102(35.8)$ \\
\hline \multicolumn{2}{|c|}{ Age (years) } \\
\hline$\leq 50$ & $111(38.9)$ \\
\hline$>50$ & $174(61.1)$ \\
\hline \multicolumn{2}{|l|}{ Location } \\
\hline colon & $133(46.7)$ \\
\hline rectal & $152(53.3)$ \\
\hline \multicolumn{2}{|c|}{ Clinical Stage } \\
\hline 1 & $47(16.5)$ \\
\hline$\|$ & $61(21.4)$ \\
\hline III & $88(30.9)$ \\
\hline IV & $89(31.2)$ \\
\hline \multicolumn{2}{|c|}{ T classification } \\
\hline $\mathrm{T1}$ & $20(7.0)$ \\
\hline $\mathrm{T} 2$ & $44(15.4)$ \\
\hline$\overline{\mathrm{T} 3}$ & $124(43.5)$ \\
\hline $\mathrm{T} 4$ & $97(34.0)$ \\
\hline \multicolumn{2}{|c|}{$\mathrm{N}$ classification } \\
\hline No & $123(43.2)$ \\
\hline$\overline{\mathrm{N} 1}$ & $90(31.6)$ \\
\hline $\mathrm{N} 2$ & $72(25.3)$ \\
\hline \multicolumn{2}{|c|}{ M classification } \\
\hline MO & $196(68.8)$ \\
\hline$\overline{M 1}$ & $89(31.2)$ \\
\hline \multicolumn{2}{|c|}{ Pathologic Differentiation } \\
\hline Poor & $58(20.4)$ \\
\hline Moderate & $205(71.9)$ \\
\hline$\overline{\text { Well }}$ & $22(7.7)$ \\
\hline
\end{tabular}

\begin{tabular}{lc}
\hline Histological Types & \\
\hline Non-mucinous adenocarcinoma & $268(94.0)$ \\
\hline mucinous adenocarcinoma & $17(6.0)$ \\
\hline Vital status (at follow-up) & $173(60.7)$ \\
\hline Alive & $112(39.3)$ \\
\hline Death (All colorectal cancer-related) & $161(56.5)$ \\
\hline Expression of MAGED1-1 & $124(43.5)$ \\
\hline Low expression
\end{tabular}

primer, $5^{\prime}$ GAAGGAATCTGAGGCTTCAG; $18 \mathrm{~S}$ was amplified as an internal control using the following primers: sense primer, $5^{\prime}$ CCTGGATACCGCAGCTAGGA; anti-sense primer, $5^{\prime}$ GCGGCGCAATACGAATGCCCC. Real-time PCR was performed using programmed parameters for the SYBR Green method (Invitrogen, Carlsbad, California, USA) to collect the fluorescent signals, heating 
at $95^{\circ} \mathrm{C}$ for $5 \mathrm{~min}$, followed by $95^{\circ} \mathrm{C}$ for $15 \mathrm{~s}, 60^{\circ} \mathrm{C}$ for $15 \mathrm{~s}$ and $72^{\circ} \mathrm{C}$ for $32 \mathrm{~s}$ for 40 cycles. All gene expression values were normalized using the housekeeping gene $18 \mathrm{~S}$ and calculated using the comparative $C_{T}$ method $\left(\Delta \Delta C_{T}\right.$ method).

\section{Western blotting}

Western blotting was performed according to standard methods as described previously [16]. MAGED1 expression was determined with anti-rabbit immunoglobulin $\mathrm{G}$ (1:2,000; Abcam, Cambridge, MA) according to the manufacturer's suggested protocols. An anti- $\alpha$ tubulin mouse monoclonal antibody (1:2,000; Boster, Wuhan, China) was used as the loading control.

\section{Immunohistochemistry (IHC)}

Immunohistochemistry was performed to study altered protein expression in 285 human colorectal cancer tissues. IHC was carried out according to standard methods as described previously [16]. Briefly, the tissue sections were deparaffinized in xylene at $37^{\circ} \mathrm{C}$ for $20 \mathrm{~min}$ and rehydrated. Endogenous peroxide was blocked by incubating the sections with $3 \%$ hydrogen peroxide in methanol for $20 \mathrm{~min}$ at $37^{\circ} \mathrm{C}$. The sections were then submerged in $10 \mathrm{mM}$ citrate buffer ( $\mathrm{pH}$ 6.0) and microwaved for antigenic retrieval, followed by incubation with rabbit anti-
MAGED1 (1:200; Millipore, Billerica, MA) overnight at $4^{\circ} \mathrm{C}$. After washing, tissue sections were treated with anti-rabbit secondary antibody for $30 \mathrm{~min}$, followed by further incubation with streptavidin horseradish peroxidase complex. The sections were developed with diaminobenzidine tetrahydrochloride (DAB) and counterstained with hematoxylin.

The proportion of the stained cells and the extent of the staining were used as criteria of evaluation. Slides were scored by two independent observers who were blinded to the patient data. For each case, at least 1,000 tumor cells were analyzed, and the percentage of positively stained tumor cells was recorded. For each sample, the proportion of MAGED1-expressing cells varied from $0 \%$ to $100 \%$, and the intensity of staining varied from weak to strong. One score was given according to the percent of positive cells as follows: $\leq 10 \%=0,>10 \%$ to $\leq$ $25 \%=1,>25 \%$ to $\leq 50 \%=2,>50 \%$ to $\leq 75 \%=3,>75 \%=4$. Another score was given according to the intensity of staining as negative $=0$, weak $=1$, moderate $=2$, or strong $=3$. A final score was then calculated by multiplying the two above scores. If the final score was equal to or less than four, the tumor was considered as having low expression; otherwise, the tumor was considered as having high expression.

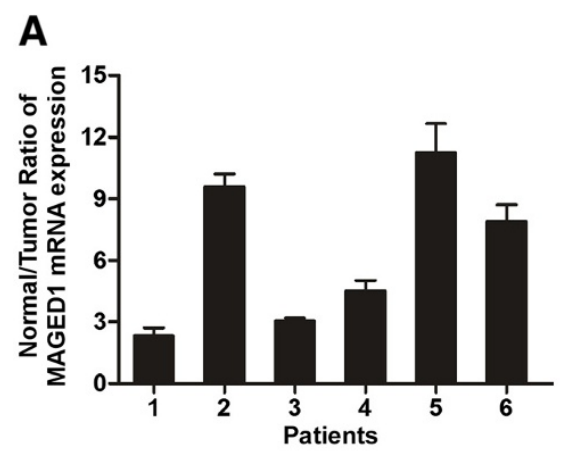

B

C
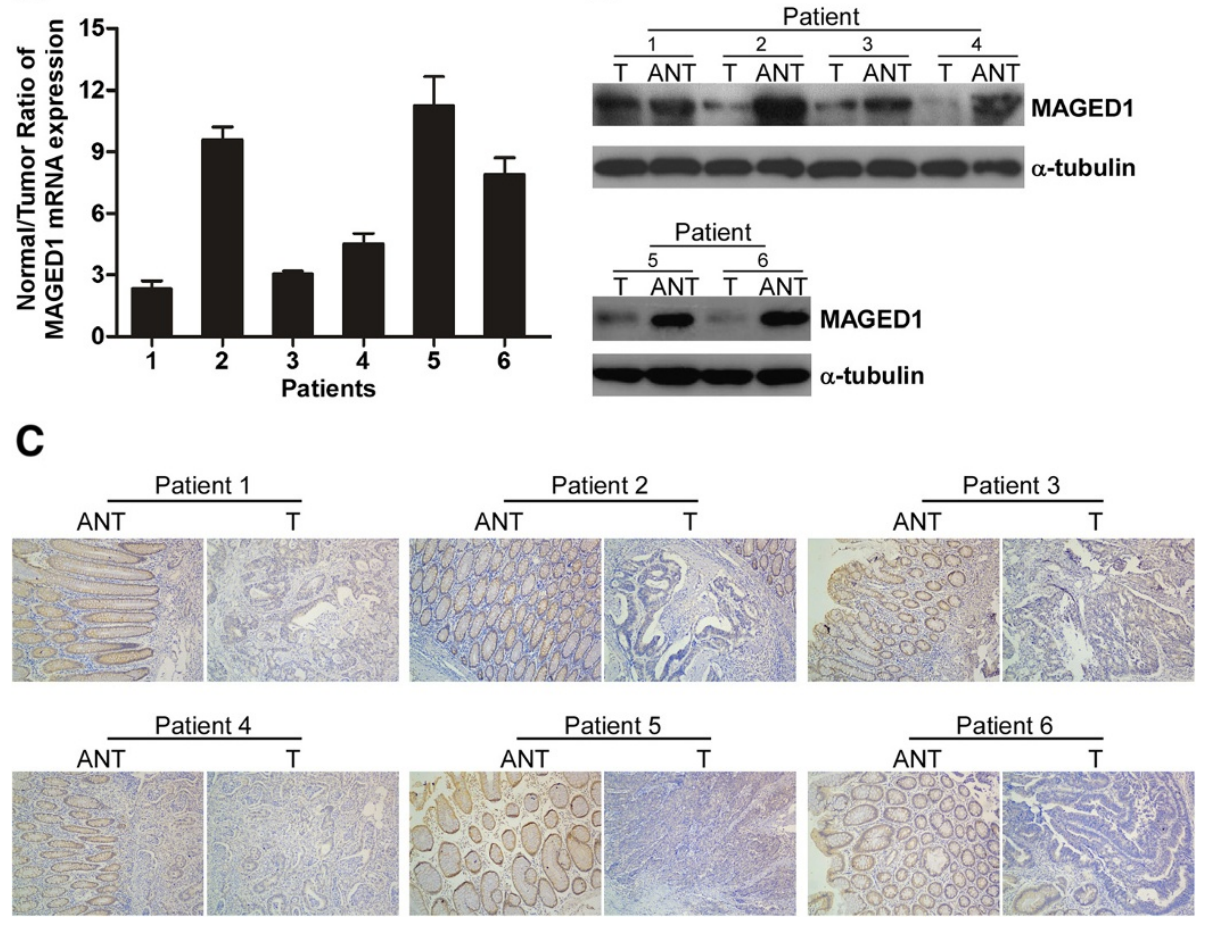

Figure 1 Decreased expression of MAGED1-1 in colorectal cancer. A, Real time RT-PCR analysis of the normal/tumor ratio of MAGED1-1 mRNA expression in each of the primary colon cancer tissues (T) and adjacent non-cancerous colon tissues (ANT) paired from the same patient. B-C, Western blotting (B) and IHC (C) analyses of MAGED1-1 protein in each of the primary colon cancer tissues (T) and adjacent non-cancerous colon tissues (ANT) paired from the same patient. 


\section{Statistical analysis}

All statistical analyses were performed using by the SPSS 16.0 statistical software package (SPSS Inc., Chicago, IL). The relationship between MAGED1 expression and the clinicopathologic characteristics was analyzed by the $\chi^{2}$ test. Survival curves were plotted by the Kaplan-Meier method and compared using the log-rank test. Survival data were evaluated using univariate and multivariate Cox regression analyses. A $p$-value of less than 0.05 was considered statistically significant in all cases.

\section{Results}

MAGED1 expression in paired colorectal cancer and non-tumorous tissues

Real-time PCR, western blotting and IHC analysis showed that MAGED1 mRNA and protein expression were significantly down-regulated in all six pairs of human colorectal cancer tissues compared with matched adjacent non-tumorous tissues (Figure 1A-C) Additional file 1: Table S1.

131 colorectal cancer and matched ANT samples derived from the 285 archival primary colorectal cancer tissues were evaluated MAGED1 protein expression by IHC analysis Additional file 2: Table S2. We defined the scores less than or equal to four, including nonexpression as low MAGED1 expression referring to their MAGED1 expression scoring system in the IHC samples, otherwise, they were considered as having high MAGED1 expression. According to the definition, the rate of low MAGED1 expression (74/131, 56.5\%) in colorectal cancer samples significantly differed from the rate in matched ANT samples (13/131, 10.0\%) $(\mathrm{p}=0.031)$. Furthermore, MAGED1 expression was down-regulated in 58.8\% (77/131) and up-regulated only in $22.1 \%(29 / 131)$ colorectal cancer tissues, compared with their paired ANT tissues according to the scoring system. These results suggest that MAGED1 expression is down-regulated in colorectal cancer tissues.

\section{Correlation between MAGED1 protein expression and clinicopathological features}

MAGED1 protein expression was evaluated by immunohistochemistry in 285 paraffin-embedded, archival primary colorectal cancer tissues. The samples included 47 cases of clinical stage I (16.5\%), 61 cases of stage II (21.4\%), 88 cases of stage III (30.9\%) and 89 cases of stage IV (31.2\%) colorectal cancer. MAGED1 protein was detected in 261 of 285 CRC cases (91.6\%), but in only 5 of 17 colorectal mucinous adenocarcinoma cases (29.4\%). According to the scoring system, low MAGED1 expression was detected in 161/285 (56.5\%) colorectal carcinomas, while the high MAGED1 expression was detected in $124 / 285$ (43.5\%).

Table 2 Correlation between MAGED1-1 expression and clinicopathological characteristics of colorectal cancer patients

\begin{tabular}{|c|c|c|c|c|}
\hline \multicolumn{2}{|c|}{ Characteristics } & \multicolumn{2}{|c|}{ MAGED1-1 } & \multirow[t]{2}{*}{ Chi-square test $P$-value } \\
\hline & & Low or none No. cases (\%) & High No. cases (\%) & \\
\hline \multirow[t]{2}{*}{ Gender } & Female & $63(39.1)$ & $39(31.5)$ & 0.213 \\
\hline & Male & $98(60.9)$ & $85(68.5)$ & \\
\hline \multirow[t]{2}{*}{ Age (years) } & $\leq 50$ & $65(40.4)$ & $46(37.1)$ & 0.625 \\
\hline & $>50$ & $96(59.6)$ & $78(62.9)$ & \\
\hline \multirow[t]{2}{*}{ Location } & colon & $70(43.5)$ & $63(50.8)$ & 0.233 \\
\hline & rectal & $91(56.5)$ & $61(49.2)$ & \\
\hline \multirow[t]{3}{*}{ Clinical Stage } & $1+\|$ & $35(21.7)$ & $73(58.9)$ & $<0.001$ \\
\hline & III & $60(68.2)$ & $28(31.8)$ & \\
\hline & IV & $66(74.2)$ & 23(25.8) & \\
\hline \multirow[t]{2}{*}{ T classification } & $\mathrm{T} 1+\mathrm{T} 2$ & $24(14.9)$ & $40(32.3)$ & 0.001 \\
\hline & $\mathrm{T} 3+\mathrm{T} 4$ & $137(85.1)$ & $84(67.4)$ & \\
\hline \multirow[t]{2}{*}{ N classification } & No & $43(26.7)$ & $80(64.5)$ & $<0.001$ \\
\hline & Yes & $118(73.3)$ & $44(35.5)$ & \\
\hline \multirow[t]{2}{*}{ M classification } & MO & $95(59.0)$ & $101(81.5)$ & $<0.001$ \\
\hline & M1 & $66(41.0)$ & $23(18.5)$ & \\
\hline \multirow[t]{3}{*}{ Pathologic Differentiation } & Poor & $44(27.3)$ & $14(11.3)$ & 0.002 \\
\hline & Moderate & $108(67.1)$ & $97(78.2)$ & \\
\hline & Well & $9(5.6)$ & $13(10.5)$ & \\
\hline \multirow[t]{2}{*}{ Histological Types } & Non-mucinous adenocarcinoma & $148(92.5)$ & $120(96.0)$ & 0.227 \\
\hline & mucinous adenocarcinoma & $12(7.5)$ & $5(4.0)$ & \\
\hline
\end{tabular}




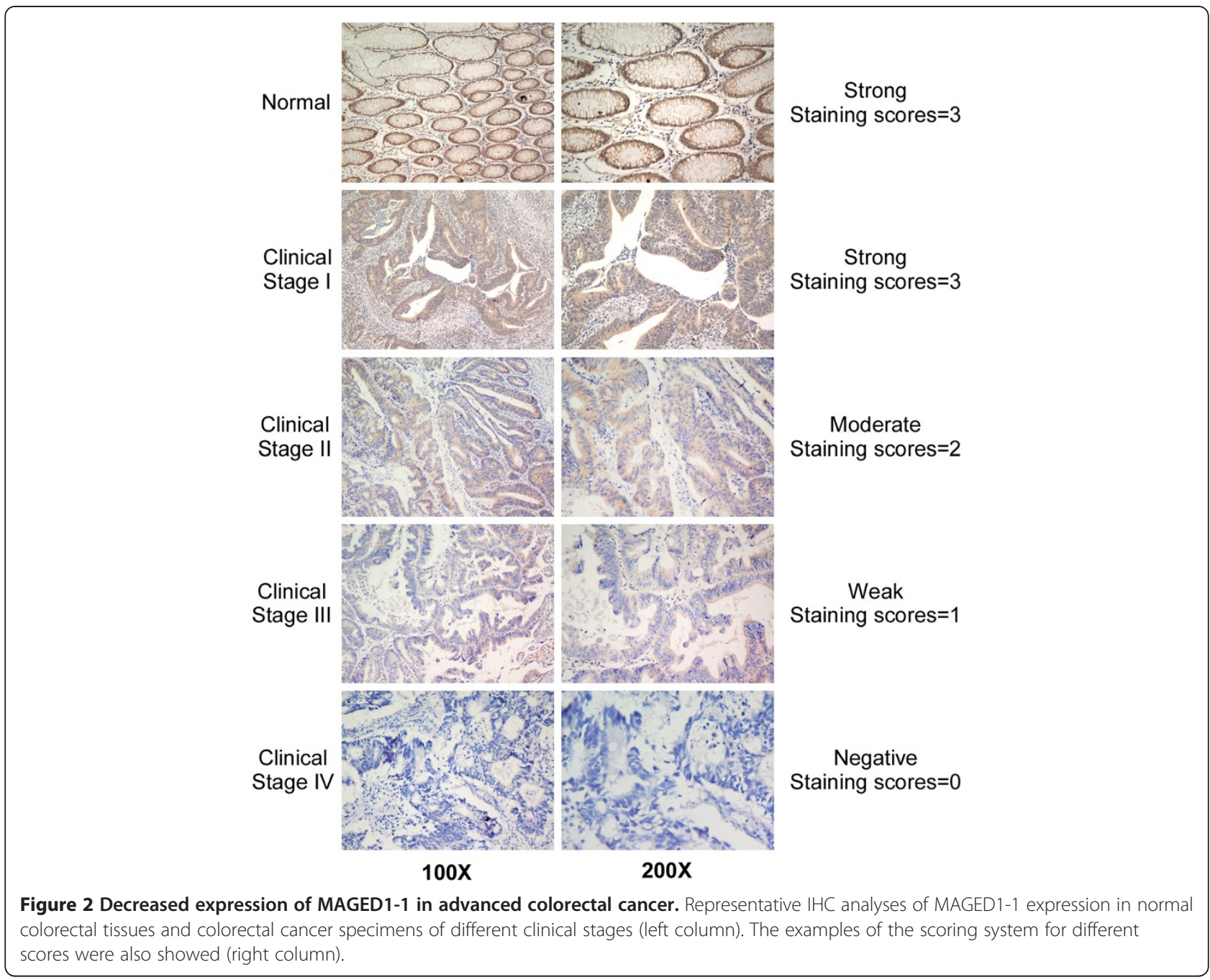

As shown in Table 2, the relationship between the MAGED1 expression and clinical characteristics was analyzed in 285 CRC cases. There was no significant correlation between MAGED1 protein expression and gender, age, tumor location, or histological types of CRC. However, MAGED1 expression was closely associated with clinical stage $(p<0.001)$, T classification $(p=0.001), \mathrm{N}$ classification $(p<0.001), \mathrm{M}$ classification $(p<0.001)$ and pathologic differentiation $(p=0.002)$.

The MAGED1 protein expression was inversely correlated with clinical stage and $\mathrm{T}$ classification. Higher staging and poor pathological differentiation were correlated with lower MAGED1 expression (Figures 2 and 3). In addition, most of the colorectal mucinous adenocarcinoma cases (12/17) were demonstrated low MAGED1 expression.

\section{Survival analysis}

A Kaplan-Meier analysis and the log-rank test were used to calculate the effects of the clinicopathological characteristics and MAGED1 expression on survival. The expression of MAGED1 in colorectal cancer was significantly correlated with patients' survival time ( $p$ $<0.001)$. Patients with lower MAGED1 expression had a shorter overall survival time (OS) than those with higher MAGED1 expression (median OS 47 months vs has not been reached, respectively; $\mathrm{p}<0.001$ ). The overall two-, three-, and five-year accumulative survival rates were $68.8 \%, 57.2 \%$, and $46.1 \%$, respectively, in cases with low MAGED1 expression and were $93.5 \%, 80.2 \%$, and $78.4 \%$, respectively, in cases with high level of MAGED1 expression(Figure 4A). Additionally, similar results were obtained in stage III and IV subgroup patients (Figure 4C), but stage I-II subgroup patients did not show the similar results (Figure 4B).

Furthermore, univariate and multivariate analyses indicated that clinical stage, pathologic differentiation, and MAGED1 expression were independent prognostic factors (Table 3), suggesting that MAGED1 may be a prognostic factor for survival in colorectal cancer patients. 


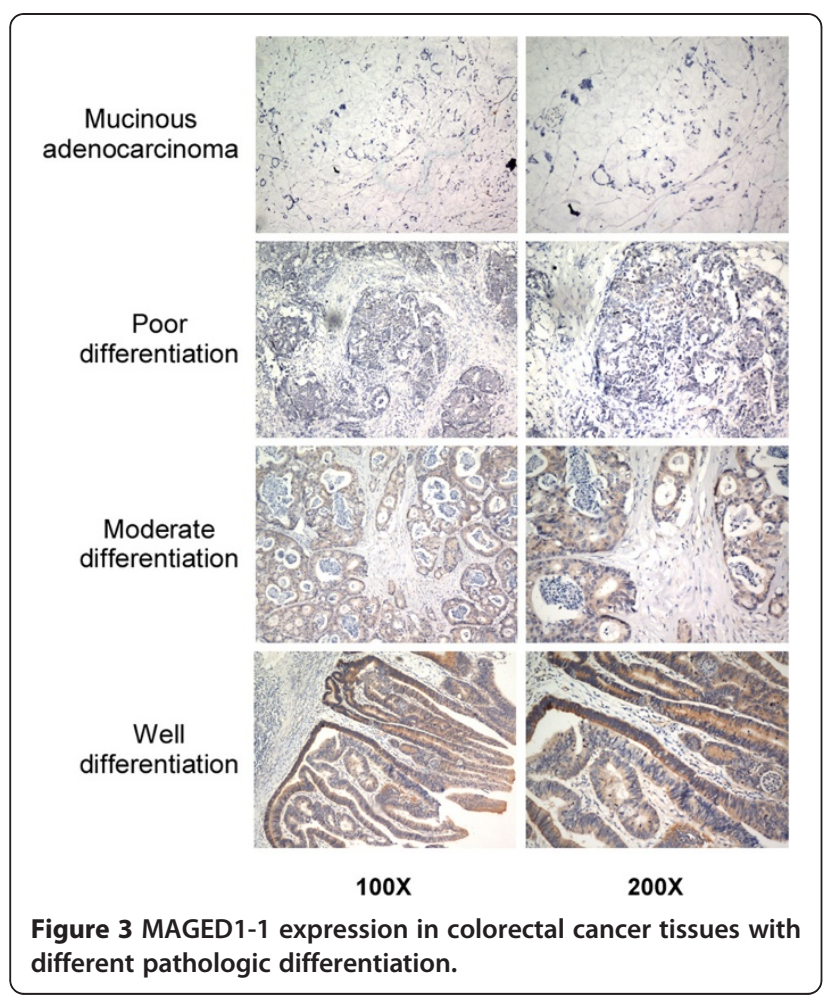

\section{Discussion}

In the present study, we demonstrated that MAGED1 expression was down-regulated at both the mRNA and protein levels in colorectal cancer tissues compared to matched adjacent non-tumorous tissues. Low levels of MAGED1 expression were more frequently observed in CRC patients with poor pathologic differentiation or those with advanced stages. This is the first study to analyze the prognostic relevance of the MAGED1 expression in colorectal carcinoma. We demonstrated that high MAGED1 expression was correlated with a better survival outcome, whereas low MAGED1 expression was correlated with a poorer survival outcome. Furthermore, MAGED1 expression was an independent prognostic factor, suggesting that MAGED1 may be a prognostic factor for survival in colorectal cancer patients.

MAGED1 expression may also be associated with the histological types in CRC. We found that MAGED1 expression was low in most of the mucinous adenocarcinomas of CRC (12/17). Conversely, the rate of low MAGED1 expression (148/268) in non-mucinous adenocarcinoma did not significantly differ from the rate of high expression (120/268). However, because we could only obtain a small number of mucinous
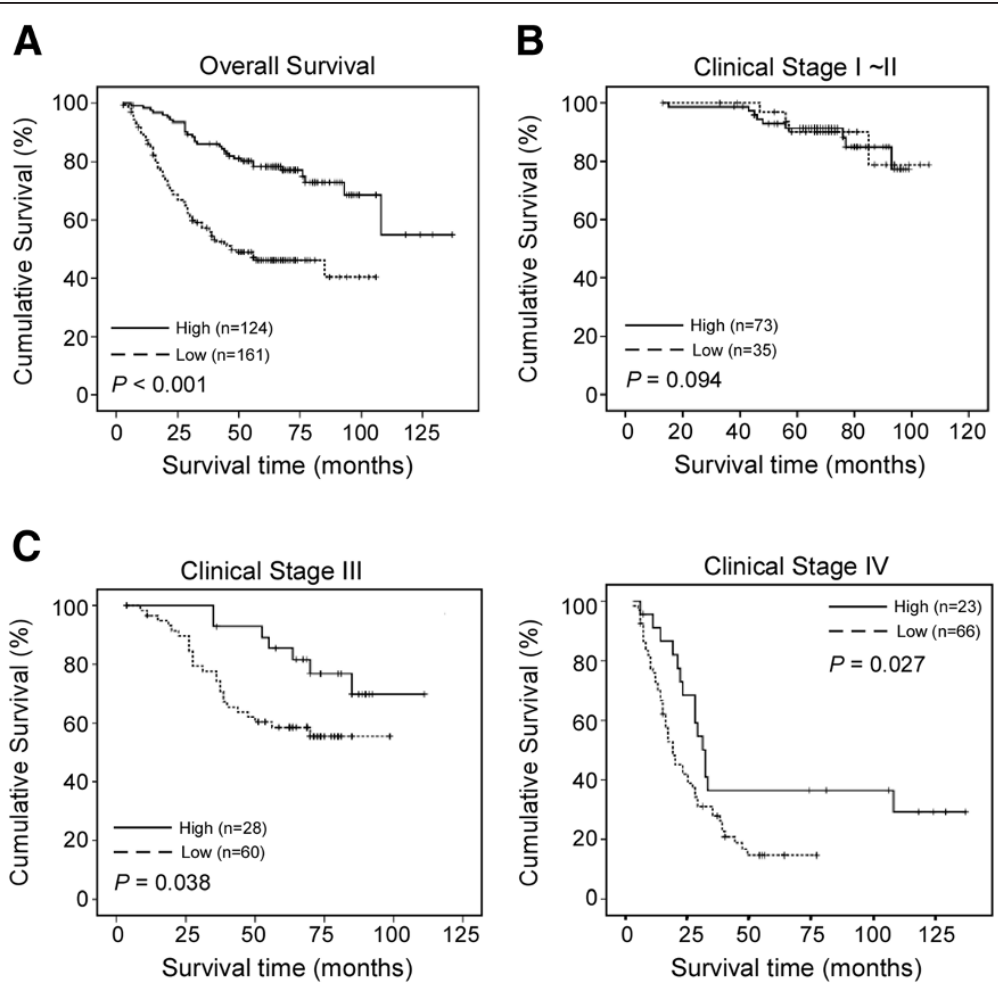

Figure 4 Kaplan-Meier curves with univariate analyses (log-rank) for patients with low MAGED1-1 expression (dotted line) versus high MAGED1-1 expression tumors (bold line). A, The overall survival of patients (clinical stages I-IV) with low/high MAGED1-1 expression. B, The overall survival of patients (clinical stages I-II) with low/high MAGED1-1 expression. C, The overall survival of patients (clinical stages III and IV) with low/high MAGED1-1 expression. 
Table 3 Univariate and multivariate analysis of various prognostic parameters in patients with colorectal cancer Cox-regression analysis

\begin{tabular}{|c|c|c|c|c|c|}
\hline \multirow[t]{2}{*}{ Variables } & \multicolumn{2}{|c|}{ Univariate analysis } & \multicolumn{3}{|c|}{ Multivariate analysis } \\
\hline & No. & $P$ value & Hazard Ratio & $95 \% \mathrm{Cl}$ & $P$ value \\
\hline MAGED1-1 & & $<0.001$ & 0.473 & $0.305-0.734$ & 0.001 \\
\hline low expression & 161 & & & & \\
\hline high expression & 124 & & & & \\
\hline Age & & 0.388 & 1.006 & $0.992-1.020$ & 0.419 \\
\hline$\leq 50$ & 111 & & & & \\
\hline$>50$ & 174 & & & & \\
\hline Gender & & 0.555 & 1.048 & $0.706-1.555$ & 0.817 \\
\hline Male & 183 & & & & \\
\hline Female & 102 & & & & \\
\hline Differentiation & & 0.012 & 0.667 & $0.460-0.965$ & 0.032 \\
\hline Poor & 58 & & & & \\
\hline Moderate & 205 & & & & \\
\hline Well & 22 & & & & \\
\hline Clinical stage & & $<0.001$ & 3.127 & $2.404-4.068$ & $<0.001$ \\
\hline 1 & 47 & & & & \\
\hline$\|$ & 61 & & & & \\
\hline III & 88 & & & & \\
\hline IV & 89 & & & & \\
\hline
\end{tabular}

adenocarcinoma samples, we were unable to demonstrate a significant correlation between the MAGED1 expression and the histological types in CRC $(p=0.227)$. The inclusion of a greater number of mucinous adenocarcinoma samples may resolve the problem.

We also failed to observe a significant relationship between the MAGED1 expression and CRC patients' survival in the clinical stages I II. We believe that this is due to the good prognosis of the early stage CRC patients and limit number of the clinical cases. However, there were significant correlations between the MAGED1 expression and overall survival in all patients and in clinical stage III and IV patients.

MAGED1 expression was also evaluated by Chung et al. in Taiwanese CRC patients, and reported MAGED1 overexpression occurred in $45 \%$ CRC patients [15]. In the present study, 131 CRC patients were enrolled to compare their MAGED1 expression between colorectal cancer tissues and paired adjacent non-tumorous tissues. The MAGED1 expression was down-regulated in 58.8\% (77/ $131)$ and up-regulated only in $22.1 \%$ (29/131) CRC patients. Compared the patients' clinical characteristics in these two studies, we found that the stage IV patients were $6.0 \%(6 / 100)$ vs $26.0 \%(34 / 131)$ in Chung et al.'s and our study, respectively. Importantly, the present study has shown that higher staging was correlated with lower MAGED1 expression. Thus, we deduce that the lower MAGED1 overexpression rate in our study was most probably because of the different distribution of clinical stages in patients. On the other hand, different research designs were performed in these two projects. Chung et al.'s study was detected MAGED1 expression on gene level; whereas our research was focus on its expression on protein level, which post-translational modifications may be involved in the expression regulation.

Different from the MAGED1, MAGED12 was reported frequently up-regulated in tumors [15,17]. It was reported that MAGED1 and -D2 RNA had different distribution during the embryonic development and brain development [18]. All these data suggested that different types of MAGE genes may play distinct roles in biochemical activities.

A circadian rhythm is an approximate 24 -h period in the biological process of living entities, controlled by endogenous clock genes $[19,20]$. Clock genes include period (per), clock (clk), Bmal1, Rev-erb $\alpha$, cryptochrome (cry), and others [21]. MAGED1 was reported to regulate the expression of Bmal1, Rev-erb $\alpha$, and E4bp4 by binding to the ROR $\alpha$ protein. The depletion of MAGED1 in vivo has been shown to cause severely dampened oscillations of Bmal1 mRNA expression, resulting in an increased the clock speed [22]

Mounting evidence shows that circadian disruption increases cancer incidence and the cancer growth rate, suggesting that circadian genes participate in the growth and development of various cancers. Per2-deficient mice showed a marked increase in tumor development and reduced apoptosis in thymocytes following $\gamma$-radiation [23]. Alternatively, overexpression of Per2 inhibited tumor proliferation in vitro [24] and in vivo [25]. Other clock genes, such as Bmal1, Clock, Cry and Rev-erbo, have also been correlated with cancer [26-29]. In the present study, we demonstrated that MAGED1 also has a close relationship with the clinical features of colorectal cancer, with higher MAGED1 expression in CRC patients correlating with better survival and vice versa. Because MAGED1 regulates Bmal1 and Rev-erb $\alpha$ expression and dampens the oscillations of Bmal1 expression, MAGED1 depletion can induce circadian rhythm disorders [22]. We hypothesize that this may be the mechanism by which MAGED1 expression correlates with the CRC patients' clinical features. However, the precise mechanism of the MAGED1 involvement in CRC development is still unclear. Thus, the further study including overexpression and knockdown of MAGED1 expression in CRC cells will be needed to explore the mechanism by which MAGED1 is involved in the development and progression of colorectal cancer and its exact regulating pathway in vitro and in vivo.

\section{Conclusion}

In the present study, we found that MAGED1 expression was significantly down-regulated in colorectal 
cancer tissues compared with adjacent non-tumorous tissues and was associated with clinical stage, $\mathrm{T}$ classification, $\mathrm{N}$ classification, $\mathrm{M}$ classification and pathologic differentiation. MAGED1 expression was significantly correlated with overall survival in colorectal cancer patients. Patients with lower MAGED1 expression had a shorter survival time than those with higher MAGED1 expression. MAGED1 may serve as a novel prognostic biomarker of human colorectal cancer.

\section{Additional files}

Additional file 1: Table S1. Clinical data of 6 patients of colorectal cancer in Figure 1.

Additional file 2: Table S2. Clinical data of 131 CRC patients compared their MAGED1 expression between the colorectal cancer tissues and the paired adjacent normal tissues.

\section{Abbreviations}

AJCC: American Joint Committee on Cancer; c-JNK: c-Jun N-terminal kinase; CRC: Colorectal cancer; DAB: Diaminobenzidine tetrahydrochloride; IHC: Immunohistochemistry; ANT: Non-tumorous tissues;

MAGED1: Melanoma antigen D1; MAGE: Melanoma antigen; OS: Overall survivalx; qPCR: Quantitative real time polymerase chain reaction; SCN: Suprachiasmatic nucleusx.

\section{Competing interests}

We have no financial or personal relationships with other people or organizations that would bias our work. No benefits in any form have been received or will be received from a commercial party related directly or indirectly to the subject of our article.

\section{Authors' contributions}

ZZL conceived the study, carried out the $\mathrm{IHC}$ and drafted the manuscript. WWJ carried out the $\mathrm{HC}$ and WB, participated in the clinical data collection of the colorectal carcinoma patients. YJ carried out the GPCR. TZJ, CDL, QMZ, LHY and WZQ participated in the clinical data collection. JY and WDS performed the statistical analysis. XRH conceived the study, participated in its design and final approval of the version to be published. All authors read and approved the final manuscript.

\section{Acknowledgements}

These works were funded by National Natural Science Foundation of China (No. 30672408 to Xu RH, No. 81000888 to Zeng ZL); The Science and Technology Department of Guangdong Province, China (No. 2009B030801020).

\section{Author details}

${ }^{1}$ State Key Laboratory of Oncology in Southern China, Guangzhou 510060, China. ${ }^{2}$ Department of Experimental Research, Sun Yat-sen University Cancer Center, Guangzhou, Guangdong 510060, China. ${ }^{3}$ Department of Medical Oncology, Sun Yat-sen University Cancer Center, Guangzhou 510060, China.

Received: 23 May 2012 Accepted: 25 August 2012

Published: 31 August 2012

\section{References}

1. van der Bruggen P, Traversari C, Chomez P, Lurquin C, De Plaen E, Van den Eynde $B$, Knuth $A$, Boon T: A gene encoding an antigen recognized by cytolytic T lymphocytes on a human melanoma. Science 1991, 254:1643-1647.

2. De Plaen E, Arden K, Traversari C, Gaforio JJ, Szikora JP, De Smet C, Brasseur $F$, van der Bruggen $P$, Lethe $B$, Lurquin $C$, et al: Structure, chromosomal localization, and expression of 12 genes of the MAGE family. Immunogenetics 1994, 40:360-369.
3. Lurquin C, De Smet C, Brasseur F, Muscatelli F, Martelange V, De Plaen E, Brasseur R, Monaco AP, Boon T: Two members of the human MAGEB gene family located in Xp21.3 are expressed in tumors of various histological origins. Genomics 1997, 46:397-408.

4. Lucas S, De Smet C, Arden KC, Viars CS, Lethe B, Lurquin C, Boon T: Identification of a new MAGE gene with tumor-specific expression by representational difference analysis. Cancer Res 1998, 58:743-752.

5. Wang X, Gao X, Xu Y: MAGED1: molecular insights and clinical implications. Ann Med 2011, 43:347-355.

6. Lucas S, Brasseur F, Boon T: A new MAGE gene with ubiquitous expression does not code for known MAGE antigens recognized by $T$ cells. Cancer Res 1999, 59:4100-4103.

7. Shiras A, Sengupta A, Shepal V: Cloning and tissue-specific gene expression studies with Dlxin-1, a newly identified transcriptional activator. Mol Cell Biol Res Commun 2001, 4:313-319.

8. Masuda Y, Sasaki A, Shibuya H, Ueno N, Ikeda K, Watanabe K: Dlxin-1, a novel protein that binds Dlx5 and regulates its transcriptional function. J Biol Chem 2001, 276:5331-5338.

9. Sasaki A, Masuda $Y$, Iwai $K$, Ikeda $K$, Watanabe $K$ : A ring finger protein praja1 regulates Dlx5-dependent transcription through its ubiquitin ligase activity for the DIx/Msx-interacting MAGE/Necdin family protein, Dlxin-1. J Biol Chem 2002, 277:22541-22546.

10. Salehi $A H$, Xanthoudakis S, Barker PA: NRAGE, a p75 neurotrophin receptor-interacting protein, induces caspase activation and cell death through a JNK-dependent mitochondrial pathway. J Biol Chem 2002 277:48043-48050.

11. Kendall SE, Battelli C, Irwin S, Mitchell JG, Glackin CA, Verdi JM: NRAGE mediates p38 activation and neural progenitor apoptosis via the bone morphogenetic protein signaling cascade. Mol Cell Biol 2005, 25:7711-7724.

12. Wen CJ, Xue B, Qin WX, Yu M, Zhang MY, Zhao DH, Gao X, Gu JR, Li CJ: hNRAGE, a human neurotrophin receptor interacting MAGE homologue, regulates $\mathrm{p} 53$ transcriptional activity and inhibits cell proliferation. FEBS Lett 2004, 564:171-176.

13. Tian XX, Rai D, Li J, Zou C, Bai Y, Wazer D, Band V, Gao Q: BRCA2 suppresses cell proliferation via stabilizing MAGE-D1. Cancer Res 2005, 65:4747-4753.

14. Reddy EM, Chettiar ST, Kaur N, Ganeshkumar R, Shepal V, Shanbhag NC, Shiras A: Dlxin-1, a member of MAGE family, inhibits cell proliferation, invasion and tumorigenicity of glioma stem cells. Cancer Gene Ther 2011 18:206-218.

15. Chung FY, Cheng TL, Chang HJ, Chiu HH, Huang MY, Chang MS, Chen CC, Yang MJ, Wang JY, Lin SR: Differential gene expression profile of MAGE family in taiwanese patients with colorectal cancer. J Surg Oncol 2010, 102:148-153.

16. Teng KY, Qiu MZ, Li ZH, Luo HY, Zeng ZL, Luo RZ, Zhang HZ, Wang ZQ, Li $\mathrm{YH}, \mathrm{Xu} \mathrm{RH}$ : DNA polymerase eta protein expression predicts treatment response and survival of metastatic gastric adenocarcinoma patients treated with oxaliplatin-based chemotherapy. J Trans/ Med 2010, 8:126.

17. Li M, Lin YM, Hasegawa S, Shimokawa T, Murata K, Kameyama M, Ishikawa O, Katagiri T, Tsunoda T, Nakamura Y, Furukawa Y: Genes associated with liver metastasis of colon cancer, identified by genome-wide cDNA microarray. Int J Oncol 2004, 24:305-312.

18. Bertrand M, Huijbers I, Chomez P, De Backer O: Comparative expression analysis of the MAGED1 genes during embryogenesis and brain development. Dev Dyn 2004, 230:325-334.

19. Panda S, Hogenesch JB, Kay SA: Circadian rhythms from flies to human. Nature 2002, 417:329-335.

20. Reppert SM, Weaver DR: Coordination of circadian timing in mammals. Nature 2002, 418:935-941.

21. Fu L, Lee CC: The circadian clock: pacemaker and tumour suppressor. Nat Rev Cancer 2003, 3:350-361.

22. Wang X, Tang J, Xing L, Shi G, Ruan H, Gu X, Liu Z, Wu X, Gao X, Xu Y: Interaction of MAGED1 with nuclear receptors affects circadian clock function. EMBO J 2010, 29:1389-1400.

23. Fu L, Pelicano H, Liu J, Huang P, Lee C: The circadian gene Period2 plays an important role in tumor suppression and DNA damage response in vivo. Cell 2002, 111:41-50.

24. Oda A, Katayose Y, Yabuuchi S, Yamamoto K, Mizuma M, Shirasou S, Onogawa T, Ohtsuka H, Yoshida H, Hayashi H, et al: Clock gene mouse period2 overexpression inhibits growth of human pancreatic cancer cells 
and has synergistic effect with cisplatin. Anticancer Res 2009, 29:1201-1209.

25. Hua H, Wang Y, Wan C, Liu Y, Zhu B, Wang X, Wang Z, Ding JM: Inhibition of tumorigenesis by intratumoral delivery of the circadian gene mPer2 in C57BL/6 mice. Cancer Gene Ther 2007, 14:815-818.

26. Oshima T, Takenoshita S, Akaike M, Kunisaki C, Fujii S, Nozaki A, Numata K Shiozawa M, Rino Y, Tanaka K, et al: Expression of circadian genes correlates with liver metastasis and outcomes in colorectal cancer. Oncol Rep 2011, 25:1439-1446.

27. Zeng ZL, Wu MW, Sun J, Sun YL, Cai YC, Huang YJ, Xian LJ: Effects of the biological clock gene Bmal1 on tumour growth and anti-cancer drug activity. J Biochem 2010, 148:319-326.

28. Hanoun M, Eisele L, Suzuki M, Greally JM, Huttmann A, Aydin S, Scholtysik R, Klein-Hitpass L, Duhrsen U, Durig J: Epigenetic silencing of the circadian clock gene CRY1 is associated with an indolent clinical course in chronic lymphocytic leukemia. PLoS One 2012, 7:e34347.

29. Iurisci I, Filipski E, Sallam H, Harper F, Guettier C, Maire I, Hassan M, lacobelli S, Levi F: Liver circadian clock, a pharmacologic target of cyclindependent kinase inhibitor seliciclib. Chronobiol Int 2009, 26:1169-1188.

doi:10.1186/1479-5876-10-18

Cite this article as: Zeng et al:: Prognostic relevance of melanoma antigen D1 expression in colorectal carcinoma. Journal of Translational Medicine 2012 10:181.

\section{Submit your next manuscript to BioMed Central and take full advantage of:}

- Convenient online submission

- Thorough peer review

- No space constraints or color figure charges

- Immediate publication on acceptance

- Inclusion in PubMed, CAS, Scopus and Google Scholar

- Research which is freely available for redistribution 